


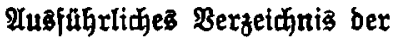

Guttentag'fden Sammlung

\section{Deutfifier æeidis-}

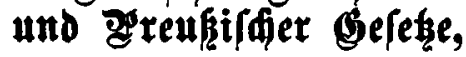

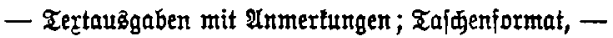
tweldeallewidtigeren beje ke in unbebingt zuberláfigen Belesesterten und in mufter. gültiger, gemeinberftänolimer Beifeer= lăutert enthălt, befinbet fich hinter bem Sad, regifíter. 


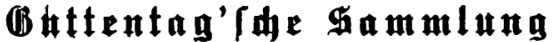

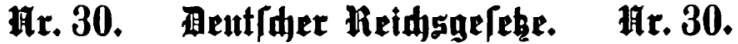 Textausgaben mit anmerfungen.}

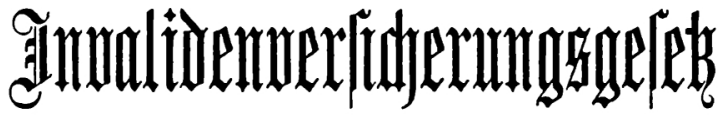 vom 13. Juli 1899}

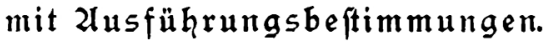

Certausgabe mit 2nmerfungen und Sadregifter bon

Dr. C. v. Moebtfe.

$\underline{\text { Behnte umgearbeitete } \mathfrak{A} \text { uflage }}$

herauzgegeben von

\&. $\mathfrak{F} \mathfrak{o} \mathfrak{l} \mathfrak{m} \mathfrak{a} \mathfrak{n} \mathfrak{n}$, Regierungß̈rat

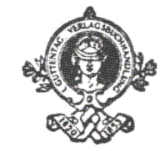

Berlin 1906.

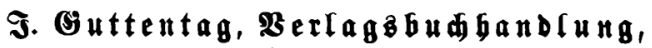
(H. m. b. $\mathfrak{b}$. 
Das Bedt der fiberfegung - an由 für đetle - Toole alls anderen Redite blelbea vorbeballer. 